\title{
Importance of Growth Monitoring by a Health Checkup in Detecting Growth Disorders in Young Children
}

\author{
Remi Kuwabara and Tatsuhiko Urakami* \\ Department of Pediatrics, Japan \\ Received: 盎: November 15, 2018; Published: ㄴㅔㅛ: November 26, 2018 \\ *Corresponding author: Tatsuhiko Urakami, Department of Pediatrics, Japan
}

\section{Introduction}

Normal growth is a sign of good health and well-being in children. Assessment of height and weight is the best indicators of child's growth as well as general heath. Abnormal growth may indicate malnutrition or the existence of underlying disease in children [1]. Some developing countries where most of children suffer from malnutrition resulted in abnormal growth. Early detection of growth failure can contribute to increase utilization of a health service resulted in improved nutritional status, reduced morbidity and reduced mortality [2]. On the other hand, in developed countries, the aim of growth monitoring is to identify children with various treatable causes of abnormal growth, who have been missed or who failed to present in clinical practice. A review of 31 studies of growth monitoring demonstrated that a single height screening could identify between 1:545 and 1:1793 new cases of potentially treatable children [3]. Despite its widespread use, the importance of growth monitoring in detecting growth disorders and its impact on child health is not well recognized [4].

Besides, even if growth monitoring is performed, children with treatable causes of abnormal growth are frequently diagnosed or treated at an inadequate older age, and they might not achieve normal or near normal height $[5,6]$. Some children are unable to get routine growth checkup at schools by staffs who are lacking in recognition of significance of growth monitoring [7]. Yardeni showed that adherence to guidelines for evaluation of growth failure in the primary clinic referring children to a specialist, a pediatric endocrinologist, was inadequate; children were frequently referred without data on previous growth, parental height and crucial laboratory data indicating physician's evaluation at primary care was lacking [8].

\section{Growth Monitoring by a Health Checkup}

Health checkups, performed at public health centers (for 3-, 6-, 18-, and 36-month-old infants), nursery schools, kindergartens and primary schools may be the best opportunity for recognizing early childhood health problems such as psychomotor-development delay and growth retardation [9-11]. In Japan all young children have opportunity to get these health checkups covered by a governmental charge. In the health checkups, we measure children's heights and weights overtime and evaluate the pattern of growth by plotting of heights and weights on the growth curve. A single height/weight measurement only identifies children whose height/weight is outside the normal range for their age. In contrast, repeated height measurements over time allow for calculation of a growth velocity and can find abnormal growth in terms of a crossing of the height centiles, thereby identifying abnormality through the pattern of growth within the individual [12]. Growth chart provides a superior measure, because changes in actual height become evident after altered growth velocities have been sustained for a period. A normal child tends to follow a given centile line; deviations in growth away from the percentile are difficult to detect over short intervals using the growth chart; this is one of the most important reasons for calculating the growth velocity [13]. Majority of countries have developed growth reference charts that are specific to their populations for use in routine clinical practice $[14,15]$. Diagnosis of short is usually based on a child's height measurement lying outside - 2 SD on a growth chart; however, exact cut-off points may vary between country and between growth charts. In Japan, short stature is defined as height Standard Deviation Score (SDS) < -2.0 SDS for age and gender based on the data collected in Japanese normal healthy children at year 2000 national survey. Growth deceleration is defined as a growth velocity $<-1.5$ SDS for age and gender (e.g. $<5 \mathrm{~cm} /$ year after the age of 5 years) or a height drop across two or more SDS on the growth chart [16].

\section{Importance of Growth Monitoring by a Health Checkup in Detecting Growth Disorders}

We previously reported the outcome of growth monitoring by health checkups in young children conducted in one of the local city in Chiba Prefecture, during 2009-2009 [17]. After that, we again analyzed the data obtained from the health checkups conducted at the same city during 2009-2016. Since 2009, we 
repeatedly performed educational activities on abnormal growth in young children, which included giving lecturers for short stature, distributing growth charts and materials concerning abnormal growth, towards nurses at public health centers and caregivers at nursery schools, kindergartens and primary schools in the provincial city, who perform the health checkups. After the educational activities, the number of children who visited the hospital with complaints of short stature dramatically increased overtime (Figure 1). Final diagnoses for abnormal growth consisted of constitutional short stature without hormonal abnormalities in $72.2 \%$, growth hormone deficiency in $13.9 \%$, short stature due to being small for gestational age in $11.1 \%$ and others, including Turner syndrome, hypothyroidism and renal insufficiency, in $2.8 \%$. Because of the visits, appropriate treatment, such as supplementation of growth hormone and nutrition/lifestyle consultation and education were introduced to the patients and family members in early childhood, which can lead to children's improved growth. Table 1 shows reasons of visiting the hospital with complaints of short stature during the study period. Of note, the most commonly reported reasons for visiting the hospital were because of a health checkup at a public health center, nursery school, kindergarten or primary school (66.7\%), followed by being referred by other clinics $(25.0 \%)$ and of patient's own accord in $8.3 \%$. It is noteworthy that the number of patients referred because of a health checkup from public health centers, nursery schools, kindergartens or primary schools evidently increased overtime after giving educational activities. These results indicate that growth monitoring by a health checkup might be a best opportunity to detect abnormal growth in early childhood, and educational activities on abnormal growth targeting health nurses, school teachers seem to be helpful in promoting detection of abnormal growth and its underlying diseases in young children. Early detection of abnormal growth could facilitate appropriate treatment and health education in early childhood, and thereby can improve growth prognosis $[2,17]$.

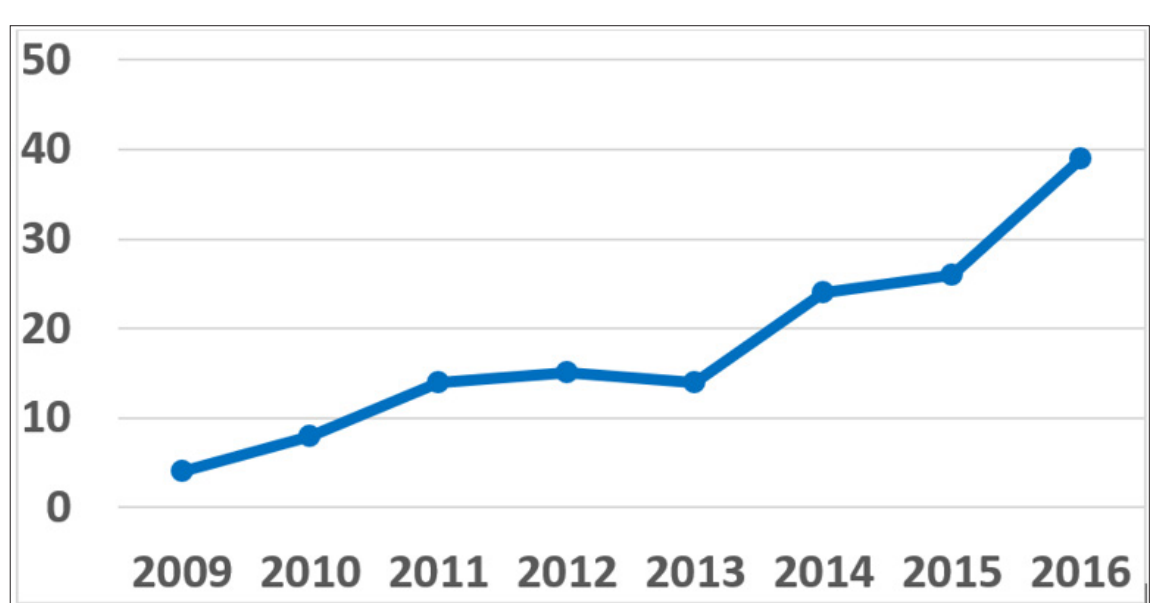

Figure 1: Change in the number of children who visited the hospital with complaints of short stature during 2009-2016.

Table 1: Reasons of visiting the hospital with complaints of short stature during 2009-2016.

\begin{tabular}{|c|c|c|c|}
\hline & Referral by Other Clinics & Health Checkup & of Patients Own Accord \\
\hline 2009 & 2 & 2 & 0 \\
\hline 2010 & 6 & 2 & 0 \\
\hline 2011 & 5 & 5 & 4 \\
\hline 2012 & 4 & 8 & 3 \\
\hline 2013 & 2 & 12 & 1 \\
\hline 2014 & 4 & 19 & 1 \\
\hline 2015 & 6 & 19 & 3 \\
\hline
\end{tabular}

\section{References}

1. Haymond M, Kappelgaard AM, Czernichow P, Biller BMK, Takano K (2013) Early recognition of growth abnormalities permitting early intervention. Acta Pediatr 102(8): 787-796.

2. Ashworth A, Shrimpton R, Jamil K (2008) Growth monitoring and promotion: Review of evidence of impact. Maternal and Child Nutrition 4(1): 86-117.

3. Fayter D, Nixon J, Hartley S (2007) A systematic review of the routine monitoring of growth in children of primary school age to identify growth-related conditions. Health Technol Assess 11(22): 1-163.
4. Hindmarsh PC, Cole TJ (2004) Height monitoring as a diagnostic test. Arch Dis Child 89: 296-297.

5. Macfarlane A (1995) Epidemiology of short stature due to growth failure. J Med Screen 2(3): 128-129.

6. (2000) American Academy of Pediatrics. Recommendations for preventive pediatric health care committee on practice and ambulatory medicine. Pediatrics 105(3): 645-646.

7. Fry T (2008) If it's worth doing, let's do it! Arch Dis Child 93(4): 267-268. 
8. Yardeni D, Loewenthal N, Limony Y, Hershkovitz E (2011) Ethnic and gender inequities in the evaluation of referred short children. Horm Res Paediatr 76(1): 50-55

9. Yokota S (2013) Meaning and necessity of health checkup in infants. Shoninaika in Japanese 45: 449-452.

10. Eto T (2013) Meaning and necessity of health checkup in school children. Shoninaika in Japanese 45: 456-459.

11. Endo I (2013) Meaning and necessity of health checkup in nursery school and kindergarten. Shoninaika in Japanese 45: 453-455.

12. Rogol AD, Clark PA, Roemmich JN (2000) Growth and pubertal development in children and adolescents: effects of diet and physical activity. Am J Clin Nutr 72(2 Suppl): 521S-528S.

13. Brook CG, Hindmarsh PC, Healy MJ (1986) A better way to detect growth failure. Br Med J (Clin Res Ed) 293(6556): 1186.

\section{ISSN: 2574-1241}

DOI: $10.26717 / B J S T R .2018 .11 .002094$

Tatsuhiko Urakami. Biomed J Sci \& Tech Res

cC (P) This work is licensed under Creative Commons Attribution 4.0 License

Submission Link: https://biomedres.us/submit-manuscript.php
14. De Onis M, Onyango A, Borghi E, Siyam A, Lutter C (2012) Worldwide implementation of the WHO child growth standards. Public Health Nutr 15(9): 1603-1610.

15. Freeman JV, Cole TJ, Chinn S, Jones PR, White EM (1995) Cross sectional stature and weight reference curves for the UK, 1990. Arch Dis Child 73(1): 17-24.

16. Isojima T, Kato N, Ito Y, Kanzaki S, Murata M (2016) Growth standard charts for Japanese children with mean and Standard Deviation (SD) values based on the year 2000 national survey. Clin Pediatr Endocrinol 25(2): 71-76.

17. Urakami T, Nishimura K, Nishimura Y, Takahashi S (2016) Education activities improve detection of growth abnormalities in young children. Pediatr Int 58: 1255-1256.

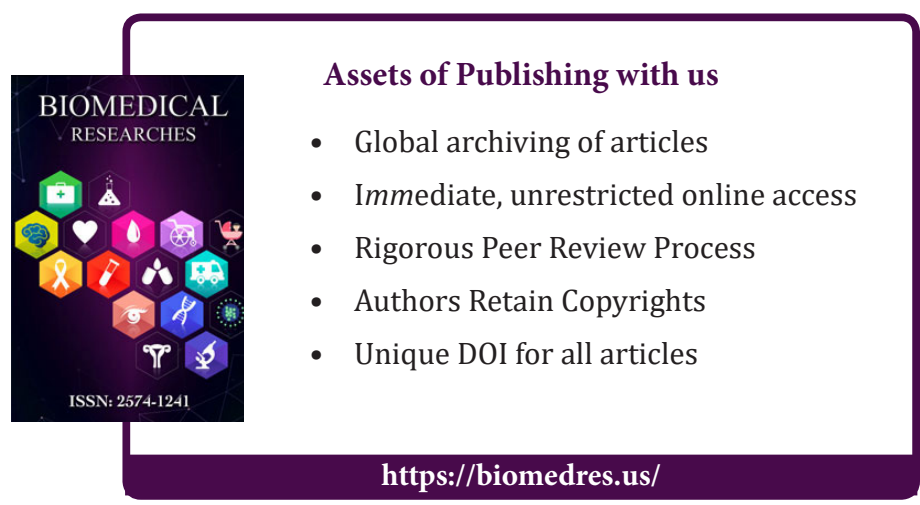

